\title{
Muscle Satellite Cells and Duchenne Muscular Dystrophy
}

\author{
Yuko Miyagoe-Suzuki ${ }^{1}$, So-ichiro Fukada ${ }^{2}$ and Shin' ichi Takeda ${ }^{1}$ \\ ${ }^{1}$ Department of Molecular Therapy, National Institute of Neuroscience, \\ National Center of Neurology and Psychiatry, \\ ${ }^{2}$ Department of Immunology, Graduate School of Pharmaceutical Sciences, \\ Osaka University, \\ Japan
}

\section{Introduction}

Muscle satellite cells are tissue-specific stem cells in skeletal muscle that play central roles in postnatal muscle growth and regeneration, and therefore are a potential source for cell therapy for Duchenne muscular dystrophy (DMD). However, to date, transplantation of satellite cells-derived myoblasts in human has not been successful. To overcome the limitations of transplantation of myoblasts, we need to better understand the molecular and cellular regulation of satellite cells. In this chapter, we summarize recent advances in satellite cell biology and its role in muscular dystrophies. Then we discuss the roles of the muscle tissue microenvironments in muscle regeneration and muscular dystrophies. Recent results emphasize that mutual interactions among myogenic cells, inflammatory cells, and interstitial mesenchymal cells are important for successful muscle regeneration. The latter two are versatile regulators of muscle regeneration. They promote muscle regeneration in healthy muscle, but when muscle fibers fail to regenerate, they promote fibrosis and fatty degeneration to ensure the continuity of the tissue. In the last part of this chapter, we discuss strategies to generate new muscle stem cells from fibroblasts by transcription factormediated reprogramming.

\section{Muscle satellite cells}

Satellite cells are skeletal muscle-specific stem cells located between the muscle basal lamina and myofibers in a quiescent and undifferentiated state (G0). Satellite cells were first identified by electron microscopy by Mauro in 1961 (Mauro 1961). Ultrastructural data suggests that $2-6 \%$ of all nuclei in humans are satellite cells (Schmalbruch \& Hellhammer 1976). Satellite cells originate from somites or cranial mesoderm and differentiate into Pax3+Pax7+ muscle progenitor cells, and then take the position of satellite cells (Gros et al 2005; Kassar-Duchossoy et al 2005; Relaix et al 2005). A recent paper, however, demonstrated that all satellite cells (MyoD-negative) originate from MyoD-positive progenitors (Kanisicak et al 2009), suggesting that satellite cells are derived from committed myogenic progenitor cells. 
During postnatal development, satellite cells divide to provide new myonuclei to growing muscle fibers (Moss \& Leblond 1971), and then enter to an undifferentiated quiescent state in adult skeletal muscle (Schultz et al 1978). In mice, vigorous muscle growth due to satellite cell division is observed until three weeks after birth (White et al 2010). During this period, the number of satellite cells decreases, and then it becomes constant for a long time to maintain skeletal muscle homeostasis.

Skeletal muscle regeneration also depends absolutely on satellite cells. When muscle is injured, satellite cells are activated, proliferate, and differentiate into myofibers, and a minor subset self-renew (Figure 1). Their dysfunction is responsible for the loss of muscle mass in muscular dystrophies or during aging. Although many studies indicate that stem cells, which are distinct from satellite cells, contribute to the production of myofibers (Ferrari et al 1998; Fukada et al 2002; Gussoni et al 1999; LaBarge \& Blau 2002), there is no doubt that satellite cells are the physiological stem cells for skeletal muscle regeneration.

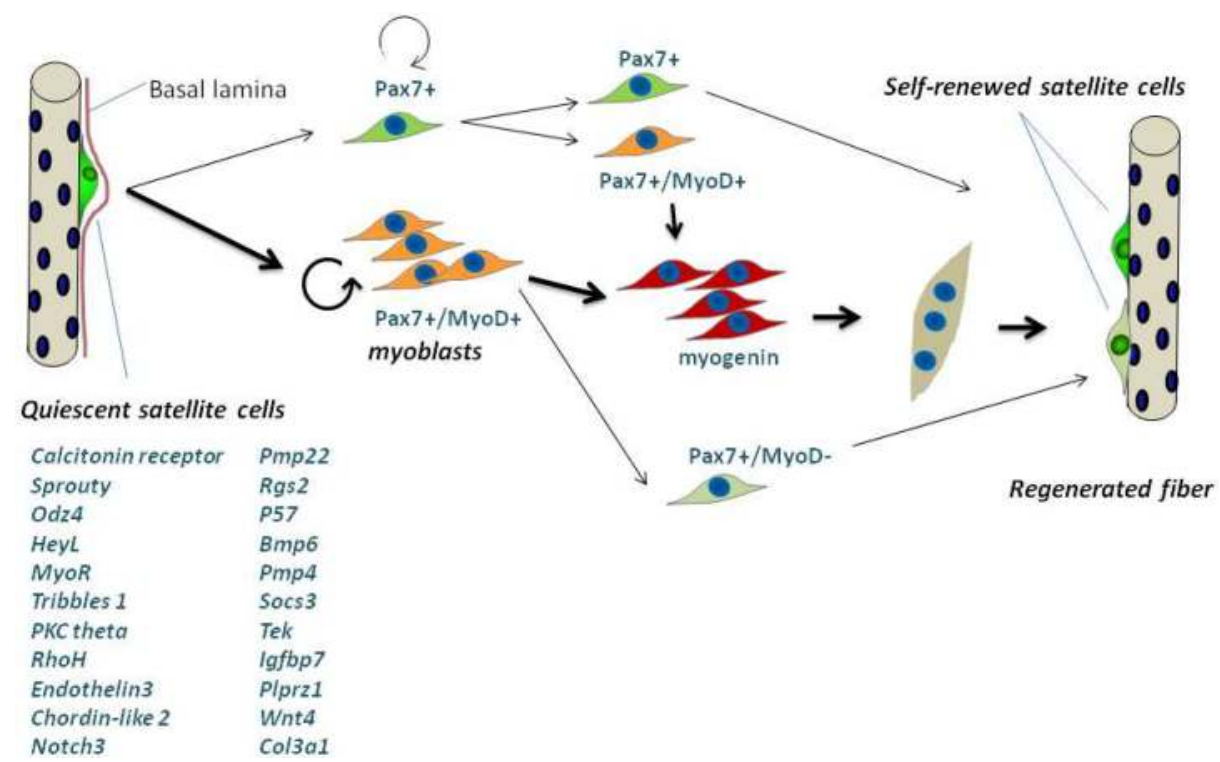

Satellite cells are in a quiescent state in uninjured adult muscle. On injury, satellite cells are activated by mitotic stimuli, vigorously proliferate to reach sufficient cell numbers, and differentiate into myofibers or fuse with pre-existing injured myofibers. A sub-set of cycling satellite cells remains uncommitted by asymmetric division and return to quiescence (Kuang et al 2007). Or a subfraction of MyoD-positive cycling satellite cells withdraw from the cell cycle and returns to the satellite cell niche (Kanisicak et al 2009). Genes up-regulated in quiescent satellite cells are shown as possible regulators of quiescence (Fukada et al 2007).

Fig. 1. Activation, proliferation, differentiation, and self-renewal of satellite cells

\subsection{Research tools}

Markers: Satellite cells were originally identified by electronic microscopy as mononuclear cells attached to myofibers, but the discovery of M-cadherin expression on satellite cells has made it easier to identify them by light microscopy (Irintchev et al 1994). Pax7 is a marker of 
satellite cells and is also critical for satellite cell biogenesis, survival and potentially selfrenewal (Seale et al 2000). Thanks to an anti-Pax7 monoclonal antibody, which identifies avian, rodent, and human satellite cells (Kawakami et al 1997), Pax7 has become the most widely used marker of satellite cells. Other markers (including c-met, syndecan 3 and 4, $\mathrm{SM} / \mathrm{C}-2.6$, integrin- $\alpha 7$, calcitonin receptor, CD34, and CXCR4) have also been established to identify satellite cells by microscopy and flow cytometry (summarized in (Boldrin et al 2010)).

Isolation: Flow cytometric and cell sorting techniques have greatly advanced stem cell studies. Fukada et al. first reported the direct isolation of satellite cells from mouse muscle using their newly developed rat monoclonal antibody, named SM/C-2.6 (Fukada et al 2004). Since then, several groups have reported the purification of satellite cells using CD34, syndecan 4, integrin- $\alpha 7$ or CXCR4 (Boldrin et al 2010; Conboy et al 2010; Fukada et al 2004; Fukada et al 2007; Montarras et al 2005; Sherwood et al 2004; Tanaka et al 2009). A singlefiber culture technique is also widely used for analysis of satellite cells (Rosenblatt et al 1995). In mouse extensor digitorum longus (EDL) muscle, approximately five satellite cells attach to one myofiber, and on isolation of fibers, they are spontaneously activated and migrate from their own myofiber. It is considered that single-fiber culture maintains the satellite cell 'niche' in in vitro condition (Collins et al 2005).

Genetic manipulation: Cre-loxP-mediated conditional inactivation of the genes makes it easy to determine the roles of regulatory molecules in a cell of a specific lineage at a specific developmental stage. The Cre-loxP-mediated lineage-tracing system is a powerful method to determine the origins and fates of muscle progenitor cells. These newly established research tools have accelerated research in satellite cell biology. In contrast to the mouse, however, a limited number of markers are available for in situ detection of satellite cells in human muscle, and human satellite cells are still isolated by the classical technique.

\subsection{Activation, proliferation, differentiation, and self-renewal of satellite cells}

Molecular regulators of the activation, proliferation, differentiation, and self-renewal of muscle satellite cells, including paired-box transcription factor Pax7, MyoD families, Six families, epigenetic regulators, or microRNAs, and numerous extracellular components are currently being elucidated (Abou-Khalil et al 2009; Buckingham \& Relaix 2007; Chen et al 2010; Crist et al 2009; Dey et al 2011; Dhawan \& Rando 2005; Juan et al 2011; Kuang et al 2008; Kuang \& Rudnicki 2008; Palacios et al 2010; Yajima et al 2010). Although these molecules are studied mainly on mouse models, similar molecules are believed to regulate human satellite cells.

Self-renewal of satellite cells with stem cell properties is an important process to maintain the stem cell pool throughout life and is one of the main subjects of recent muscle biology research, but it is largely unknown when and how satellite cells self-renew during the regeneration process. Asymmetrical division is proposed to be among the mechanisms by which satellite cells give rise to both stem cells and precursor cells (Conboy \& Rando 2002; Conboy et al 2007; Kuang et al 2008; Kuang et al 2007; Shinin et al 2006). It is also possible that some of the activated/proliferating MyoD-positive satellite cells return to the 'niche' of the satellite cells in a stochastic manner. Using MyoDicre knockin mice and R26R-EYFP or R26R- $\beta$ gal reporter mice, Kanisicak et al. reported that $99 \%$ of satellite cells in limb and body 
wall muscles originate from MyoD+ progenitors. Their findings suggest that committed MyoD+ myoblasts can return to a dormant state by suppressing MyoD and up-regulating Pax7 (Kanisicak et al 2009). This finding supports the stochastic model and explains well the heterogeneity in myogenic potential within a satellite cell population. Satellite cell activity is impaired in DMD, and how dystrophic environments perturb self-renewal of satellite cells remains to be determined.

Satellite cell behavior is thought to be mainly regulated by the environment. Satellite cells/myoblasts stop dividing just after the size of the regenerated fibers becomes comparable to that of the uninjured muscle and differentiate into myofibers or begin to return to quiescence (Fukada et al 2007; Shea et al 2010). The molecules that signal between the microenvironment and satellite cells are currently being elucidated. Interestingly, Ang1/Tie-2 signaling is such a candidate to regulate self-renewal of satellite cells by controlling the return to quiescence of a subset of them (Abou-Khalil et al 2009).

\subsection{Quiescence of satellite cells}

Satellite cells are quiescent in uninjured adult muscle. Maintenance of quiescence is important because disruption of cellular quiescence of stem cells leads to a loss of the stem cell pool and impairs tissue repair, but the molecular regulations of satellite cell dormancy are just beginning to be elucidated.

Pax7: Pax7 is highly expressed in quiescent satellite cells and over-expressed Pax7 promote a return to quiescence through repression of MyoD and myogenin (Olguin \& Olwin 2004; Olguin et al 2007). Therefore, Pax7 is thought to be central to the maintenance of quiescence. A recent study using a conditional gene inactivation system in mice showed that when Pax7 is inactivated in adult mice, mutant satellite cells can proliferate and reoccupy the sublaminal niche (Lepper et al 2009). Lepper et al. further showed that Pax7 is required in juveniles up to the point when progenitor cells make the transition to quiescence (Lepper et al 2009).

Calcitonin/calcitonin receptor: Fukada et al. performed genome-wide gene expression analysis of quiescent satellite cells freshly isolated from mouse muscle, and reported the molecular signature of quiescent satellite cells (Fukada et al 2007). The authors newly identified genes that are expressed specifically in quiescent satellite cells but down-regulated on activation (including calcitonin receptor(CTR), Odz4, HeyL/Hesr3, MyoR, tribbles1, PKC theta, Rho H, endothelin 3)(Figure 1), and demonstrated that calcitonin/calcitonin receptor signaling is involved in the maintenance of quiescence of satellite cells (Fukada et al 2007).

Notch: Notch signaling plays a critical role in maintenance of quiescent satellite cells. The hesr (hes-related, also known as hey/herp/hrt/gridlock/chf) families of bHLH transcriptional repressor genes are the primary target of Notch signaling. Fukada at al. demonstrated that genetic ablation of both Hesr1 and Hesr3 genes results in a loss of the satellite cell pool and impairs muscle regeneration (Fukada et al., 2011). Intriguingly, satellite cells lacking both Hesr 1 and Hesr3 expression ectopically express a proliferation marker, MyoD, and a differentiation marker, myogenin.

Sprouty1 (Spry1): Sprouty1 (Spry1) is a candidate molecule involved in the maintenance of satellite cells. In contrast to Pax7 and Hesr1/Hesr3, however, Sprouty1 is not required for 
maintenance of the satellite cell pool in uninjured muscle, but it is indispensable for the return to quiescence of the self-renewing satellite cells during repair (Abou-Khalil \& Brack 2010; Shea et al 2010). Sprouty1 is a negative regulator of receptor tyrosine kinase (RTK) signaling, which suggests that Sprouty1 plays a role in sensing growth factors within the muscle and regulating satellite cell quiescence during muscle regeneration.

Signals from myofibers seem most important to induce cycling satellite cells to return to the quiescent state and maintain them in the niche, because CTR-positive or Sprouty1-positive satellite cells reappear only at a late stage of regeneration (Fukada et al 2007; Shea et al 2010). Interaction between myofibers and satellite cells through cadherins would be required for the maintenance of the quiescent state of satellite cells. Although M-cadherinnull mice did not show any abnormality in skeletal growth and regeneration, the other cadherin families are thought to compensate for the lack of M-cadherin-deficiency (Hollnagel et al 2002).

\subsection{Regulation of satellite cells by non-myogenic cells}

Mesenchymal cells in skeletal muscle regulate muscle satellite cells. We previously reported a novel side population subset: CD31(-)CD45(-) SP cells (Uezumi et al 2006). They are resident in skeletal muscle and are activated and vigorously proliferate during muscle regeneration. RT-PCR analysis suggested that CD31(-)CD45(-) SP cells are of mesenchymal lineage, and differentiate into adipocytes, osteogenic cells, and muscle cells after specific induction in vitro (Uezumi et al 2006). Motohashi et al. further showed by co-transplantation experiments that CD31(-)CD45(-) SP cells promote proliferation and migration of grafted myoblasts (Motohashi et al 2008). They also showed that CD31(-)CD45(-) SP cells produce a variety of cytokines, cytokine receptors, extra-cellular matrix proteins, matrix met al oproteinase families, and other wound healing-related molecules (Motohashi et al 2008). More recently, Joe et al. identified bipotent fibro/adipogenic progenitor cells (FAPs) in muscle. FAPs are CD31(-)CD45(-) $\alpha 7$ integrin(-) CD34(-)Sca1(+), and promote differentiation of satellite cells (Joe et al 2010). Although we speculate that CD31(-)CD45(-) SP cells overlap with FAPs, the relationship between them remains to be determined. Interestingly, these studies suggest that mesenchymal progenitor cells themselves are also regulated by the muscle environment.

Macrophages are also versatile regulators of muscle regeneration, exhibiting opposing activities (pro- and anti-inflammatory effects) (Arnold et al 2007; Mann et al 2011; Segawa et al 2008; Tidball \& Villalta 2010; Vidal et al 2008; Villalta et al 2009). Possible interaction among macrophages, mesenchymal progenitor cells, and myogenic cells are summarized in Figure 2.

\section{Satellite cells and Duchenne muscular dystrophy}

Duchenne muscular dystrophy is caused by the absence of dystrophin and characterized by progressive muscle weakness and chronic cycles of degeneration and regeneration of skeletal muscle. Satellite cells and their progeny, myoblasts are thought to gradually lose their proliferative and differentiative capacity, and be eventually exhausted in Duchenne muscular dystrophy, due to repeated activation and proliferation and limited self-renewal capacity (Blau et al 1983; Blau et al 1985; Heslop et al 2000). As a result, muscle regeneration 


\section{A. Acute injury}

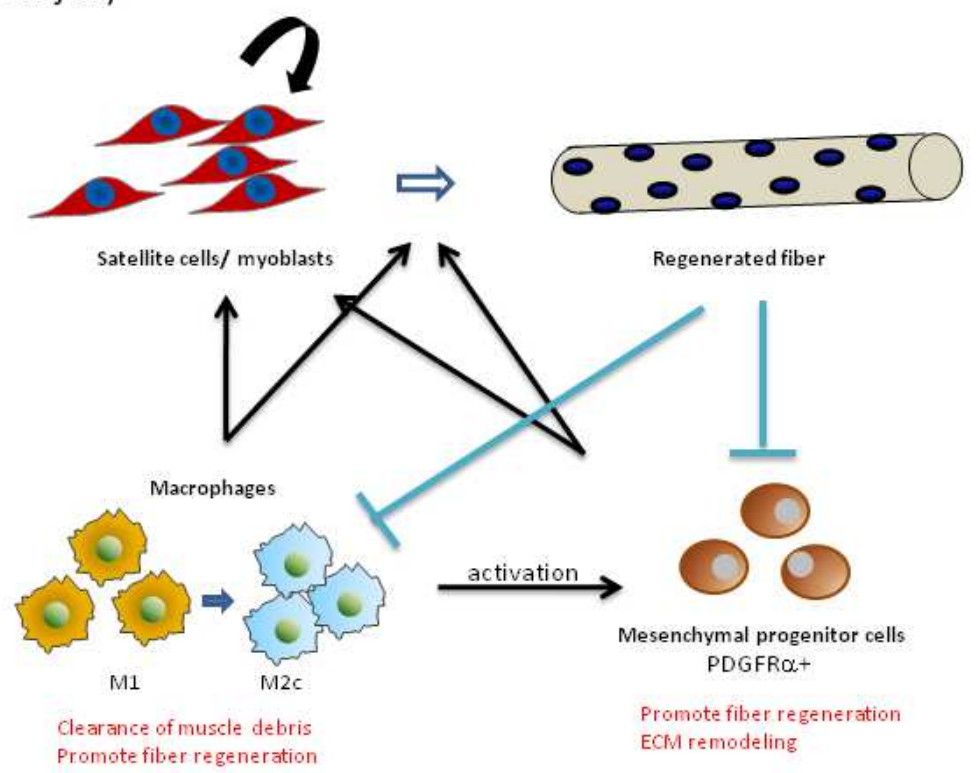

\section{B. Muscular dystrophy}



A. In acute muscle injury, resident and infiltrating macrophages first secret pro-inflammatory cytokines, express iNOS, and clear dead fibers by phagocytosis (M1), then release antiinflammatory cytokines and stimulate myogenesis and fiber growth (M2c: anti-inflammatory macrophages ) (Mann et al 2011; Tidball \& Villalta 2010). Mesenchymal progenitor cells are rapidly activated, extensively proliferate, and promote proliferation, migration, and differentiation of satellite cells, but almost completely vanish at the completion of myofiber regeneration. M2 macrophages produce pro-fibrotic molecules such as TGF- $\beta$ and stimulate mesenchymal cells to 
produce ECM components and ECM-remodeling factors. Successfully regenerated muscle fibers, in turn, seem to calm activated macrophages and mesenchymal cells down.

B. In dystrophic muscle, macrophages continue to release pro-inflammatory cytokines. M2a (alternatively activated) macrophages, which are usually associated with tissue repair, woundhealing and fibrosis, are reported to be abundant in fibrotic muscle of mdx mice, and proposed to be involved in fibrosis development (Vidal et al 2008; Villalta et al 2009). In prolonged inflammation, mesenchymal progenitors differentiate into adipocytes and fibroblastic cells, and promote fatty infiltration and fibrosis. A recent study suggests that regenerated muscle fibers directly inhibit this phenotypic conversion.

Fig. 2. Mutual regulations among macrophages, mesenchymal progenitor cells, and satellite cells in muscle regeneration (model)

is impaired in the advanced state of the disease, and muscle tissue is gradually replaced by adipose and fibrotic tissues. At this stage, gene therapy, exon-skipping therapy, and pharmacological therapy are not effective. Importantly, recent studies show that poor or aberrant muscular regeneration of the diseased muscle cannot be simply ascribed to the exhaustion of satellite cells. Berg et al. recently reported that satellite cells from 10-monthold golden retriever muscular dystrophy dogs, which show severe phenotypes at this age, show proliferation and differentiation potentials equivalent to those of wild-type littermates in vitro (Berg et al 2011). The authors suggest that pathological changes in the muscle environment rather than cell-intrinsic defects may be largely implicated in the eventual failure of satellite cell efficacy in vivo. For example, prolonged inflammation in dystrophic muscle exposes satellite cells to pro-fibrotic, pro-adipogenic cytokines, and suppresses the myogenic function of satellite cells (reviewed in (Mann et al 2011; Tidball \& Villalta 2010). In the next session, we focus on satellite cells in dystrophic conditions, and review the cellular origin of adipogenesis and fibrosis in disease environments. For direct effects of the gene mutations on satellite cells in other muscular dystrophies, please refer to a recent review by Morgan \& Zammit (Morgan \& Zammit 2010).

\subsection{Fibrosis and adipocyte infiltration in DMD muscle}

DMD muscle is characterized by chronic inflammation, endomysial fibrosis and adipocyte infiltration (fatty degeneration). It is widely accepted that fibrosis and adipocyte infiltration inhibit not only skeletal muscle function, but also myogenic activities of satellite cells, thereby diminish the amount of target tissue available for therapeutic intervention. Therefore, inhibition of fibrosis and adipogenesis is expected to attenuate DMD progression and increase the success of new cell and gene-based therapies (Mann et al 2011). In fact, many papers show that pharmacological inhibition of fibrosis in $m d x$ mice ameliorates the pathology in dystrophin-deficient cardiac and skeletal muscle (Bish et al 2011; Cohn et al 2007; Rafael-Fortney et al 2011; Taniguti et al 2011).

The cellular origin of fatty infiltration has been controversial. Previous studies suggested that satellite cells transdifferentiate into adipocytes and/or fibroblastic cells in pathological conditions. Li et al. reported that TGF- $\beta$, a profibrotic cytokine, in skeletal muscle induces the differentiation of $\mathrm{C} 2 \mathrm{C} 12$ cells, a myogenic cell line, into fibrotic cells (Li et al 2004). Alexakis et al. also indicated that collagen types I and III were expressed in primary myoblasts derived from mouse satellite cells (Alexakis et al 2007). In contrast, Uezumi et al. (Uezumi et al 2010) and Joe et al.(Joe et al 2010) demonstrated that platelet-derived growth factor receptor alpha (PDGFR $\alpha$ )-positive mesenchymal progenitors or muscle-resident 
fibro/adipogenic progenitor cells (FAPs) are distinct from satellite cells, and show a strong predisposition towards the generation of adipocytes, and readily differentiate into adipocyte under pathological environments.

Uezumi et al. further provide evidence suggesting that PDGFR $\alpha+$ mesenchymal progenitors also contribute to fibrosis. The authors demonstrated that PDGFR $\alpha+$ cells, but not PDGFR $\alpha-$ cells produce fibrosis-related molecules in vivo after transplantation, and transforming growth factor (TGF)- $\beta$ s, known as potent profibrotic cytokines, induce the expression of fibrosis-related genes in PDGFR $\alpha+$ mesenchymal progenitors, but not in myogenic cells (Uezumi et al 2011). Importantly, imatinib, an inhibitor of several tyrosine kinases including c-abl, c-kit, and PDGFRs, was demonstrated to ameliorate dystrophic phenotypes in $m d x$ mice by suppressing the phosphorylation of PDGFR $\alpha$ (Huang et al 2009). In addition, constitutively active PDGFR $\alpha$-receptor knock-in mice exhibited systemic fibrosis including skeletal muscle tissue (Olson \& Soriano 2009). Because PDGFR $\alpha$ is exclusively expressed in mesenchymal progenitors in skeletal muscle, these results strongly suggest that PDGFR $\alpha+$ mesenchymal progenitors but not satellite cells contribute to connective tissue accumulation in dystrophic muscle.

Mesenchymal progenitor cells never differentiate into adipocytes or produce fibrosis-related molecules in healthy muscle. Why do they preferentially differentiate into collagenproducing fibroblasts or adipocyte in DMD muscle? One plausible explanation is prolonged inflammation due to continuous degeneration/regeneration cycles of muscle and the phenotypic change of macrophages (Mann et al 2011; Tidball \& Villalta 2010). Although macrophages promote muscle regeneration (Segawa et al 2008; Tidball \& Villalta 2010), macrophages in the advanced stage of $\mathrm{mdx}$ are reported to contribute to the development of fibrosis and fatty degeneration by secreting pro-fibrotic and pro-adipogenic cytokines (Mann et al 2011; Tidball \& Villalta 2010).

\subsection{Limited regenerative potential of human satellite cells}

In Duchenne muscular dystrophy, dystrophin deficiency leads to progressive lethal skeletal muscle degeneration. But, dystrophin deficiency does not recapitulate DMD in mice (mdx), which show active regeneration of damaged muscle throughout life, a much milder phenotype than DMD patients, and an almost normal life span.

Sacco et al. demonstrated that mdx mice lacking telomerase activity show shortened telomeres in muscle cells and a severe dystrophic phenotype (Sacco et al 2010). Together with a previous report of a 14-fold greater shortening of telomeres in DMD patients relative to healthy individuals (Decary et al 2000), these studies suggest that a difference in the length of telomeres between humans $(5-15 \mathrm{kbs})$ and mice $(>40 \mathrm{kbs})$ greatly explains the difference in proliferative potential of muscle satellite cells between DMD patients and mdx mice.

On the other hand, Fukada et al. showed that the phenotype of mdx became much more severe when mdx was crossed to with the DBA/ 2 strain (Fukada et al 2010). The $m d x$ mouse $\left(\mathrm{C} 57 \mathrm{BL} / 10-D m d^{m d x}\right)$, first described in 1984, arose in an inbred colony of C57BL/10 mice. Importantly, the proliferation of DBA/2 satellite cells was inferior to that of C57BL/6 (a widely used strain akin to C57BL/10) satellite cells, indicating that the properties of satellite cells and mdx phenotypes greatly depend on the genetic background of the mice. 


\section{Cell therapy for DMD}

In 1989, Partridge et al. demonstrated that transplantation of normal myoblasts restores dystrophin in dystrophin-deficient mdx mice (Partridge et al 1989). In spite of this success, the subsequent myoblast transplantation performed on DMD boys was unsuccessful (Law et al 1992; Mendell et al 1995; Tremblay et al 1993). In this section, we discuss the problems of myoblast-transplantation and other cell sources for cell therapy of DMD.

\subsection{Myoblasts transplantation therapy (MTT)}

Myoblasts transplantation therapy (MTT) for DMD was tried in the early 90's, but the results were disappointing (Law et al 1992; Mendell et al 1995; Tremblay et al 1993). Although the high-density myoblast transplantation recently performed by Tremblay's team in Canada is promising in some aspects, the effects are still local due to the limited migration and poor survival of grafted cells (Mouly et al 2005; Skuk \& Tremblay 2011). In addition, expansion in vitro is shown to gradually reduce the regenerative activity of satellite cells (Ikemoto et al 2007; Montarras et al 2005). This is probably because satellite cells have limited proliferative capacities, which are exhausted by expansion in culture. However, currently used culture conditions might simply be inappropriate for the expansion of satellite cells because satellite cells in their niche robustly regenerate injured muscle (Collins et al 2005). Recently, Gilbert et al. pointed out the importance of substrate elasticity in culture (Gilbert et al 2010). When satellite cells were cultured on soft hydrogel substrates that mimic the elasticity of in vivo muscle, the cultured cells contributed more extensively to muscle regeneration, indicating that the culture system has much room for improvement. Myoblast transfer therapy is expected to restore muscle function in relatively localized muscle diseases such as oculo-pharyngeal muscular dystrophy (OPMD), by using autologous myoblasts from relatively spared patient muscles (Mouly et al 2005).

\subsection{Making satellite cells from non-myogenic cells by reprogramming}



If myogenic cells can be efficiently induced from patient-derived pluripotent stem cells (iPS cells), these cells are candidate sources for cell therapy of muscular dystrophies. On the other hand, direct reprogramming using transcription factors has been reported to successfully convert fibroblasts into clinically relevant cells (neurons, cardiocytes, hepatocytes, chondrocytes, etc). MyoD is a master regulator of myogenesis, but not sufficient to generate myogenic stem cells with high proliferative potential. OKSM: Oct4, Klf4, Sox2 and c-Myc.

Fig. 3. New cell sources for cell therapy of muscular dystrophies 


\subsection{New cell source for cell therapy of DMD}

It is difficult to prepare a large quantity of satellite cells from a donor. In addition, expansion of satellite cells in vitro reduces the regenerative activity (Ikemoto et al 2007; Montarras et al 2005). Mesoangioblasts or muscle-derived stem cells (MDSC) are multi-potent stem cells distinct from satellite cells that have been demonstrated to be highly proliferative and able to be delivered to the musculature of the whole body. However, the number of cells, as starting materials, required to restore dystrophin expression in cardiac and respiratory muscle and improve performance of DMD patients remains to be determined in clinical trials. On the other hand, transcription factor-mediated reprogramming of somatic cells into myogenic cells is now being vigorously investigated, and is expected to be a feasible technique in the near future. Two different strategies are proposed to generate myogenic cells from somatic cells (Figure 3). One is to reprogram somatic cells of patients into pluripotent stem cells (iPS cells) using Yamanaka factors, and then induce them to differentiate into transplantable myogenic cells. The other strategy is to directly induce fibroblasts to differentiate into myogenic cells without first passing the cells through a pluripotent state.

\subsubsection{Induced pluripotent stem cells (iPS cells)}

In 2006, Takahashi and Yamanaka reported that only four factors (Oct4, Klf4, Sox2, and cMyc, are sufficient to reprogram somatic cells into embryoni stem (ES) cell-like pluripotent stem cells (Takahashi \& Yamanaka 2006). The induced cells are called induced pluripotent cells (iPS cells). The next year, the same group and Thompson's group reported the establishment of human iPS cells from skin fibroblasts using slightly different sets of reprogramming factors (Takahashi et al 2007; Yu et al 2007). This technique is groundbreaking, because it enables us to obtain patient-specific iPS cells with pluripotency. Muscular dystrophy patient-specific iPS cells were first reported by Park et al. (Park et al 2008). iPS cells derived from the patients showed human ES-like properties, and therefore may be a promising cell source for cell therapy. If myogenic stem cells can be constantly induced from iPS cells, there will be no limitation in the number of the cells for transplantation. In addition, although a controversial report of immunogenicity appeared recently (Zhao et al 2011), autologous iPS cells are expected to produce tissue-specific stem / progenitor cells that evoke no immune reaction in the host.

\subsubsection{Muscle differentiation of ES/iPS cells}

The success of iPS cell-based therapy for DMD depends on the efficiency of induction of myogenic progenitor cells from iPS cells. Pax3 and Pax7 have been shown to be a powerful way to derive transplantable myogenic cells from mouse ES cells (Darabi et al 2008; Darabi et al 2011). However, for a clinical trial, integration of viral vectors into the host genome is not desirable. One possibility to avoid the use of viral vectors is to replace Pax3 or Pax7 activity with small bioactive molecules. Purification of myogenic cells from differentiating iPS culture is also important for safe cell transplantation because a culture contains both differentiated and undifferentiated cells. Contamination with undifferentiated cells can cause tumor formation in the host. A research group at Kyoto University described a strategy to sort myogenic cells from differentiating mouse ES cells (Chang et al 2009) or mouse iPS cells (Mizuno et al 2010). The authors cultured embryoid bodies in muscle differentiation medium (10\% fetal bovine serum and 5\% horse serum in DMEM) for six days and then plated them on Matrigel, and sorted SM/C-2.6-positive cells by FACS before cell transplantation. SM/C-2.6 is a rat monoclonal antibody useful to isolate satellite cells from 
mouse muscle (Fukada et al 2004). Not all SM/C-2.6-positive cells are myogenic, but the fraction is enriched in myogenic stem cells. Both strategies are promising, but human ES/iPS cells respond to the differentiation signal differently from their mouse equivalents. In addition, human ES/iPS cells differentiate more slowly than their mouse counterparts. In fact, the myogenic differentiation protocol described by Chang et al. for mouse ES/iPS cells was not efficient for human iPS cells (data not shown), and the condition need to be further explored.

\subsubsection{Direct reprogramming of fibroblasts by myogenic transcription factors}

iPS technology stimulated researchers to seek an appropriate combination of transcriptional factors to reprogram somatic cells into therapeutically relevant cell types in vitro and in vivo (Hiramatsu et al 2011; Ieda et al 2010; Sekiya \& Suzuki 2011; Szabo et al 2010; Vierbuchen et al 2010). However, we already know how to induce myogenic cells from fibroblasts. In 1989, Weintraub and colleagues demonstrated that MyoD is sufficient to convert fibroblasts and numerous other cell types into skeletal muscle (Weintraub et al 1989). This was the first example of transcription factor-based reprogramming of the cell, but this technology has not been successfully applied to regenerative medicine. Recently, Kimura et al. reported that MyoD mediated conversion of fibroblasts in situ (Kimura et al 2008). The authors first introduced a tamoxifen-inducible MyoD expression cassette together with a muscle promoter-derived dystrophin expression cassette into mdx-derived fibroblasts, and then transplanted them into mdx muscle. Injection of tamoxifen into the mdx mice resulted in the appearance of dystrophin-positive myofibers in transplanted muscle, but many of them were small and clustered in the interstitial space. Pax3, Pax7 and their co-factors are also candidate transcription factors to reprogram fibroblasts into highly proliferative, systemically transplantable stem cells.

\section{Conclusion}

Satellite cells are skeletal muscle-specific stem cells involved in muscle growth and regeneration. Their dysfunctions are reported in several pathological conditions. Recent studies emphasize that, in addition to exhaustion of satellite cells, the microenvironment greatly influences satellite cell behaviors. Therefore both satellite cells and their microenvironment are targets of regenerative medicine. Satellite cells are also expected to be a source for cell transplantation therapy, but preparation of viable satellite cells from donors in a large quantity is not realistic. To overcome this limitation, the transcription factor-mediated reprogramming technique is now in the spotlight. MyoD was the first direct reprogramming factor discovered. However, it is not sufficient to generate high-quality myogenic cells from fibroblasts. To overcome this problem, we must fully understand the molecular and cellular regulation of satellite cells. Fortunately, we are now starting to do this.

\section{Acknowledgment}

We thank all members of Department of Molecular Therapy for valuable discussion.

\section{References}

Abou-Khalil R, Brack AS. 2010. Muscle stem cells and reversible quiescence: the role of sprouty. Cell Cycle 9:2575-80 
Abou-Khalil R, Le Grand F, Pallafacchina G, Valable S, Authier FJ, et al. 2009. Autocrine and paracrine angiopoietin $1 /$ Tie-2 signaling promotes muscle satellite cell selfrenewal. Cell Stem Cell 5:298-309

Alexakis C, Partridge T, Bou-Gharios G. 2007. Implication of the satellite cell in dystrophic muscle fibrosis: a self-perpetuating mechanism of collagen overproduction. Am J Physiol Cell Physiol 293:C661-9

Arnold L, Henry A, Poron F, Baba-Amer Y, van Rooijen N, et al. 2007. Inflammatory monocytes recruited after skeletal muscle injury switch into antiinflammatory macrophages to support myogenesis. J Exp Med 204:1057-69

Berg Z, Beffa LR, Cook DP, Cornelison DD. 2011. Muscle satellite cells from GRMD dystrophic dogs are not phenotypically distinguishable from wild type satellite cells in ex vivo culture. Neuromuscul Disord 21:282-90

Bish LT, Yarchoan M, Sleeper MM, Gazzara JA, Morine KJ, et al. 2011. Chronic losartan administration reduces mortality and preserves cardiac but not skeletal muscle function in dystrophic mice. PLoS One 6:e20856

Blau HM, Webster C, Pavlath GK. 1983. Defective myoblasts identified in Duchenne muscular dystrophy. Proc Natl Acad Sci U S A 80:4856-60

Blau HM, Webster C, Pavlath GK, Chiu CP. 1985. Evidence for defective myoblasts in Duchenne muscular dystrophy. Adv Exp Med Biol 182:85-110

Boldrin L, Muntoni F, Morgan JE. 2010. Are human and mouse satellite cells really the same? J Histochem Cytochem 58:941-55

Buckingham M, Relaix F. 2007. The role of Pax genes in the development of tissues and organs: Pax3 and Pax7 regulate muscle progenitor cell functions. Annu Rev Cell Dev Biol 23:645-73

Chang H, Yoshimoto M, Umeda K, Iwasa T, Mizuno Y, et al. 2009. Generation of transplantable, functional satellite-like cells from mouse embryonic stem cells. FASEB J 23:1907-19

Chen JF, Tao Y, Li J, Deng Z, Yan Z, et al. 2010. microRNA-1 and microRNA-206 regulate skeletal muscle satellite cell proliferation and differentiation by repressing Pax7. J Cell Biol 190:867-79

Cohn RD, van Erp C, Habashi JP, Soleimani AA, Klein EC, et al. 2007. Angiotensin II type 1 receptor blockade attenuates TGF-beta-induced failure of muscle regeneration in multiple myopathic states. Nat Med 13:204-10

Collins CA, Olsen I, Zammit PS, Heslop L, Petrie A, et al. 2005. Stem cell function, selfrenewal, and behavioral heterogeneity of cells from the adult muscle satellite cell niche. Cell 122:289-301

Conboy IM, Rando TA. 2002. The regulation of Notch signaling controls satellite cell activation and cell fate determination in postnatal myogenesis. Dev Cell 3:397-409

Conboy MJ, Cerletti M, Wagers AJ, Conboy IM. 2010. Immuno-analysis and FACS sorting of adult muscle fiber-associated stem/precursor cells. Methods Mol Biol 621:165-73

Conboy MJ, Karasov AO, Rando TA. 2007. High incidence of non-random template strand segregation and asymmetric fate determination in dividing stem cells and their progeny. PLoS Biol 5:e102

Crist CG, Montarras D, Pallafacchina G, Rocancourt D, Cumano A, et al. 2009. Muscle stem cell behavior is modified by microRNA-27 regulation of Pax3 expression. Proc Natl Acad Sci U S A 106:13383-7

Darabi R, Gehlbach K, Bachoo RM, Kamath S, Osawa M, et al. 2008. Functional skeletal muscle regeneration from differentiating embryonic stem cells. Nat Med 14:134-43 
Darabi R, Pan W, Bosnakovski D, Baik J, Kyba M, Perlingeiro RC. 2011. Functional Myogenic Engraftment from Mouse iPS Cells. Stem Cell Rev

Decary S, Hamida CB, Mouly V, Barbet JP, Hentati F, Butler-Browne GS. 2000. Shorter telomeres in dystrophic muscle consistent with extensive regeneration in young children. Neuromuscul Disord 10:113-20

Dey BK, Gagan J, Dutta A. 2011. miR-206 and -486 induce myoblast differentiation by downregulating Pax7. Mol Cell Biol 31:203-14

Dhawan J, Rando TA. 2005. Stem cells in postnatal myogenesis: molecular mechanisms of satellite cell quiescence, activation and replenishment. Trends Cell Biol 15:666-73

Ferrari G, Cusella-De Angelis G, Coletta M, Paolucci E, Stornaiuolo A, et al. 1998. Muscle regeneration by bone marrow-derived myogenic progenitors. Science 279:1528-30

Fukada S, Higuchi S, Segawa M, Koda K, Yamamoto Y, et al. 2004. Purification and cellsurface marker characterization of quiescent satellite cells from murine skeletal muscle by a novel monoclonal antibody. Exp Cell Res 296:245-55

Fukada S, Miyagoe-Suzuki Y, Tsukihara H, Yuasa K, Higuchi S, et al. 2002. Muscle regeneration by reconstitution with bone marrow or fetal liver cells from green fluorescent protein-gene transgenic mice. J Cell Sci 115:1285-93

Fukada S, Morikawa D, Yamamoto Y, Yoshida T, Sumie N, et al. 2010. Genetic background affects properties of satellite cells and $\mathrm{mdx}$ phenotypes. Am J Pathol 176:2414-24

Fukada S, Uezumi A, Ikemoto M, Masuda S, Segawa M, et al. 2007. Molecular signature of quiescent satellite cells in adult skeletal muscle. Stem Cells 25:2448-59

Fukada S, Yamaguchi M, Kokubo H, Ogawa R, Uezumi A, et al. 2011. Hesr1 and Hesr3 are essential to generate undifferentiated quiescent satellite cells and to maintain satellite cell numbers. Development. 138:4609-19.

Gilbert PM, Havenstrite KL, Magnusson KE, Sacco A, Leonardi NA, et al. 2010. Substrate elasticity regulates skeletal muscle stem cell self-renewal in culture. Science 329:1078-81

Gros J, Manceau M, Thome V, Marcelle C. 2005. A common somitic origin for embryonic muscle progenitors and satellite cells. Nature 435:954-8

Gussoni E, Soneoka Y, Strickland CD, Buzney EA, Khan MK, et al. 1999. Dystrophin expression in the mdx mouse restored by stem cell transplantation. Nature 401:390-4

Heslop L, Morgan JE, Partridge TA. 2000. Evidence for a myogenic stem cell that is exhausted in dystrophic muscle. J Cell Sci 113 ( Pt 12):2299-308

Hiramatsu K, Sasagawa S, Outani H, Nakagawa K, Yoshikawa H, Tsumaki N. 2011. Generation of hyaline cartilaginous tissue from mouse adult dermal fibroblast culture by defined factors. J Clin Invest 121:640-57

Hollnagel A, Grund C, Franke WW, Arnold HH. 2002. The cell adhesion molecule M-cadherin is not essential for muscle development and regeneration. Mol Cell Biol 22:4760-70

Huang P, Zhao XS, Fields M, Ransohoff RM, Zhou L. 2009. Imatinib attenuates skeletal muscle dystrophy in mdx mice. Faseb J 23:2539-48

Ieda M, Fu JD, Delgado-Olguin P, Vedantham V, Hayashi Y, et al. 2010. Direct reprogramming of fibroblasts into functional cardiomyocytes by defined factors. Cell 142:375-86

Ikemoto M, Fukada S, Uezumi A, Masuda S, Miyoshi H, et al. 2007. Autologous transplantation of SM/C-2.6(+) satellite cells transduced with micro-dystrophin CS1 cDNA by lentiviral vector into mdx mice. Mol Ther 15:2178-85

Irintchev A, Zeschnigk M, Starzinski-Powitz A, Wernig A. 1994. Expression pattern of Mcadherin in normal, denervated, and regenerating mouse muscles. Dev Dyn 199:326-37

Joe AW, Yi L, Natarajan A, Le Grand F, So L, et al. 2010. Muscle injury activates resident fibro/adipogenic progenitors that facilitate myogenesis. Nat Cell Biol 12:153-63 
Juan AH, Derfoul A, Feng X, Ryall JG, Dell'Orso S, et al. 2011. Polycomb EZH2 controls selfrenewal and safeguards the transcriptional identity of skeletal muscle stem cells. Genes Dev 25:789-94

Kanisicak O, Mendez JJ, Yamamoto S, Yamamoto M, Goldhamer DJ. 2009. Progenitors of skeletal muscle satellite cells express the muscle determination gene, MyoD. Dev Biol 332:131-41

Kassar-Duchossoy L, Giacone E, Gayraud-Morel B, Jory A, Gomes D, Tajbakhsh S. 2005. Pax3/Pax7 mark a novel population of primitive myogenic cells during development. Genes Dev 19:1426-31

Kawakami A, Kimura-Kawakami M, Nomura T, Fujisawa H. 1997. Distributions of PAX6 and PAX7 proteins suggest their involvement in both early and late phases of chick brain development. Mech Dev 66:119-30

Kimura E, Han JJ, Li S, Fall B, Ra J, et al. 2008. Cell-lineage regulated myogenesis for dystrophin replacement: a novel therapeutic approach for treatment of muscular dystrophy. Hum Mol Genet 17:2507-17

Kuang S, Gillespie MA, Rudnicki MA. 2008. Niche regulation of muscle satellite cell selfrenewal and differentiation. Cell Stem Cell 2:22-31

Kuang S, Kuroda K, Le Grand F, Rudnicki MA. 2007. Asymmetric self-renewal and commitment of satellite stem cells in muscle. Cell 129:999-1010

Kuang S, Rudnicki MA. 2008. The emerging biology of satellite cells and their therapeutic potential. Trends Mol Med 14:82-91

LaBarge MA, Blau HM. 2002. Biological progression from adult bone marrow to mononucleate muscle stem cell to multinucleate muscle fiber in response to injury. Cell 111:589-601

Law PK, Goodwin TG, Fang Q, Duggirala V, Larkin C, et al. 1992. Feasibility, safety, and efficacy of myoblast transfer therapy on Duchenne muscular dystrophy boys. Cell Transplant 1:235-44

Lepper C, Conway SJ, Fan CM. 2009. Adult satellite cells and embryonic muscle progenitors have distinct genetic requirements. Nature 460:627-31

Li Y, Foster W, Deasy BM, Chan Y, Prisk V, et al. 2004. Transforming growth factor-beta1 induces the differentiation of myogenic cells into fibrotic cells in injured skeletal muscle: a key event in muscle fibrogenesis. Am J Pathol 164:1007-19

Mann CJ, Perdiguero E, Kharraz Y, Aguilar S, Pessina P, et al. 2011. Aberrant repair and fibrosis development in skeletal muscle. Skelet Muscle 1:21

Mauro A. 1961. Satellite cell of skeletal muscle fibers. J Biophys Biochem Cytol 9:493-5

Mendell JR, Kissel JT, Amato AA, King W, Signore L, et al. 1995. Myoblast transfer in the treatment of Duchenne's muscular dystrophy. N Engl J Med 333:832-8

Mizuno Y, Chang H, Umeda K, Niwa A, Iwasa T, et al. 2010. Generation of skeletal muscle stem/progenitor cells from murine induced pluripotent stem cells. FASEB J 24:2245-53

Montarras D, Morgan J, Collins C, Relaix F, Zaffran S, et al. 2005. Direct isolation of satellite cells for skeletal muscle regeneration. Science 309:2064-7

Morgan JE, Zammit PS. 2010. Direct effects of the pathogenic mutation on satellite cell function in muscular dystrophy. Exp Cell Res 316:3100-8

Moss FP, Leblond CP. 1971. Satellite cells as the source of nuclei in muscles of growing rats. Anat Rec 170:421-35

Motohashi N, Uezumi A, Yada E, Fukada S, Fukushima K, et al. 2008. Muscle CD31(-) CD45(-) side population cells promote muscle regeneration by stimulating proliferation and migration of myoblasts. Am J Pathol 173:781-91 
Mouly V, Aamiri A, Perie S, Mamchaoui K, Barani A, et al. 2005. Myoblast transfer therapy: is there any light at the end of the tunnel? Acta Myol 24:128-33

Olguin HC, Olwin BB. 2004. Pax-7 up-regulation inhibits myogenesis and cell cycle progression in satellite cells: a potential mechanism for self-renewal. Dev Biol 275:375-88

Olguin HC, Yang Z, Tapscott SJ, Olwin BB. 2007. Reciprocal inhibition between Pax7 and muscle regulatory factors modulates myogenic cell fate determination. J Cell Biol 177:769-79

Olson LE, Soriano P. 2009. Increased PDGFRalpha activation disrupts connective tissue development and drives systemic fibrosis. Dev Cell 16:303-13

Palacios D, Mozzetta C, Consalvi S, Caretti G, Saccone V, et al. 2010. TNF/p38alpha/polycomb signaling to Pax7 locus in satellite cells links inflammation to the epigenetic control of muscle regeneration. Cell Stem Cell 7:455-69

Park IH, Arora N, Huo H, Maherali N, Ahfeldt T, et al. 2008. Disease-specific induced pluripotent stem cells. Cell 134:877-86

Partridge TA, Morgan JE, Coulton GR, Hoffman EP, Kunkel LM. 1989. Conversion of mdx myofibres from dystrophin-negative to -positive by injection of normal myoblasts. Nature 337:176-9

Rafael-Fortney JA, Chimanji NS, Schill KE, Martin CD, Murray JD, et al. 2011. Early treatment with lisinopril and spironolactone preserves cardiac and skeletal muscle in duchenne muscular dystrophy mice. Circulation 124:582-8

Relaix F, Rocancourt D, Mansouri A, Buckingham M. 2005. A Pax3/Pax7-dependent population of skeletal muscle progenitor cells. Nature 435:948-53

Rosenblatt JD, Lunt AI, Parry DJ, Partridge TA. 1995. Culturing satellite cells from living single muscle fiber explants. In Vitro Cell Dev Biol Anim 31:773-9

Sacco A, Mourkioti F, Tran R, Choi J, Llewellyn M, et al. 2010. Short telomeres and stem cell exhaustion model Duchenne muscular dystrophy in mdx/mTR mice. Cell 143:1059-71

Schmalbruch H, Hellhammer U. 1976. The number of satellite cells in normal human muscle. Anat Rec 185:279-87

Schultz E, Gibson MC, Champion T. 1978. Satellite cells are mitotically quiescent in mature mouse muscle: an EM and radioautographic study. J Exp Zool 206:451-6

Seale P, Sabourin LA, Girgis-Gabardo A, Mansouri A, Gruss P, Rudnicki MA. 2000. Pax7 is required for the specification of myogenic satellite cells. Cell 102:777-86

Segawa M, Fukada S, Yamamoto Y, Yahagi H, Kanematsu M, et al. 2008. Suppression of macrophage functions impairs skeletal muscle regeneration with severe fibrosis. Exp Cell Res 314:3232-44

Sekiya S, Suzuki A. 2011. Direct conversion of mouse fibroblasts to hepatocyte-like cells by defined factors. Nature 475:390-3

Shea KL, Xiang W, LaPorta VS, Licht JD, Keller C, et al. 2010. Sprouty1 regulates reversible quiescence of a self-renewing adult muscle stem cell pool during regeneration. Cell Stem Cell 6:117-29

Sherwood RI, Christensen JL, Conboy IM, Conboy MJ, Rando TA, et al. 2004. Isolation of adult mouse myogenic progenitors: functional heterogeneity of cells within and engrafting skeletal muscle. Cell 119:543-54

Shinin V, Gayraud-Morel B, Gomes D, Tajbakhsh S. 2006. Asymmetric division and cosegregation of template DNA strands in adult muscle satellite cells. Nat Cell Biol 8:677-87 
Skuk D, Tremblay JP. 2011. Intramuscular cell transplantation as a potential treatment of myopathies: clinical and preclinical relevant data. Expert Opin Biol Ther 11:359-74

Szabo E, Rampalli S, Risueno RM, Schnerch A, Mitchell R, et al. 2010. Direct conversion of human fibroblasts to multilineage blood progenitors. Nature 468:521-6

Takahashi K, Tanabe K, Ohnuki M, Narita M, Ichisaka T, et al. 2007. Induction of pluripotent stem cells from adult human fibroblasts by defined factors. Cell 131:861-72

Takahashi K, Yamanaka S. 2006. Induction of pluripotent stem cells from mouse embryonic and adult fibroblast cultures by defined factors. Cell 126:663-76

Tanaka KK, Hall JK, Troy AA, Cornelison DD, Majka SM, Olwin BB. 2009. Syndecan-4expressing muscle progenitor cells in the SP engraft as satellite cells during muscle regeneration. Cell Stem Cell 4:217-25

Taniguti AP, Pertille A, Matsumura CY, Santo Neto H, Marques MJ. 2011. Prevention of muscle fibrosis and myonecrosis in mdx mice by suramin, a TGF-beta1 blocker. Muscle Nerve 43:82-7

Tidball JG, Villalta SA. 2010. Regulatory interactions between muscle and the immune system during muscle regeneration. Am J Physiol Regul Integr Comp Physiol 298:R1173-87

Tremblay JP, Malouin F, Roy R, Huard J, Bouchard JP, et al. 1993. Results of a triple blind clinical study of myoblast transplantations without immunosuppressive treatment in young boys with Duchenne muscular dystrophy. Cell Transplant 2:99-112

Uezumi A, Fukada S, Yamamoto N, Takeda S, Tsuchida K. 2010. Mesenchymal progenitors distinct from satellite cells contribute to ectopic fat cell formation in skeletal muscle. Nat Cell Biol 12:143-52

Uezumi A, Ito T, Morikawa D, Shimizu N, Yoneda T, et al. 2011.Fibrosis and adipogenesis originate from a common mesenchymal progenitor in skeletal muscle. J Cell Sci. 124: 3654-64.

Uezumi A, Ojima K, Fukada S, Ikemoto M, Masuda S, et al. 2006. Functional heterogeneity of side population cells in skeletal muscle. Biochem Biophys Res Commun 341:864-73

Vidal B, Serrano AL, Tjwa M, Suelves M, Ardite E, et al. 2008. Fibrinogen drives dystrophic muscle fibrosis via a TGFbeta/alternative macrophage activation pathway. Genes Dev 22:1747-52

Vierbuchen T, Ostermeier A, Pang ZP, Kokubu Y, Sudhof TC, Wernig M. 2010. Direct conversion of fibroblasts to functional neurons by defined factors. Nature 463:1035-41

Villalta SA, Nguyen HX, Deng B, Gotoh T, Tidball JG. 2009. Shifts in macrophage phenotypes and macrophage competition for arginine metabolism affect the severity of muscle pathology in muscular dystrophy. Hum Mol Genet 18:482-96

Weintraub H, Tapscott SJ, Davis RL, Thayer MJ, Adam MA, et al. 1989. Activation of muscle-specific genes in pigment, nerve, fat, liver, and fibroblast cell lines by forced expression of MyoD. Proc Natl Acad Sci U S A 86:5434-8

White RB, Bierinx AS, Gnocchi VF, Zammit PS. 2010. Dynamics of muscle fibre growth during postnatal mouse development. BMC Dev Biol 10:21

Yajima H, Motohashi N, Ono Y, Sato S, Ikeda K, et al. 2010. Six family genes control the proliferation and differentiation of muscle satellite cells. Exp Cell Res 316:2932-44

Yu J, Vodyanik MA, Smuga-Otto K, Antosiewicz-Bourget J, Frane JL, et al. 2007. Induced pluripotent stem cell lines derived from human somatic cells. Science 318:1917-20

Zhao T, Zhang ZN, Rong Z, Xu Y. 2011. Immunogenicity of induced pluripotent stem cells. Nature 474:212-5 




\author{
Muscular Dystrophy \\ Edited by Dr. Madhuri Hegde
}

ISBN 978-953-51-0603-6

Hard cover, 544 pages

Publisher InTech

Published online 09, May, 2012

Published in print edition May, 2012

With more than 30 different types and subtypes known and many more yet to be classified and characterized, muscular dystrophy is a highly heterogeneous group of inherited neuromuscular disorders. This book provides a comprehensive overview of the various types of muscular dystrophies, genes associated with each subtype, disease diagnosis, management as well as available treatment options. Though each different type and subtype of muscular dystrophy is associated with a different causative gene, the majority of them have overlapping clinical presentations, making molecular diagnosis inevitable for both disease diagnosis as well as patient management. This book discusses the currently available diagnostic approaches that have revolutionized clinical research. Pathophysiology of the different muscular dystrophies, multifaceted functions of the involved genes as well as efforts towards diagnosis and effective patient management, are also discussed. Adding value to the book are the included reports on ongoing studies that show a promise for future therapeutic strategies.

\title{
How to reference
}

In order to correctly reference this scholarly work, feel free to copy and paste the following:

Yuko Miyagoe-Suzuki, So-ichiro Fukada and Shin'ichi Takeda (2012). Muscle Satellite Cells and Duchenne Muscular Dystrophy, Muscular Dystrophy, Dr. Madhuri Hegde (Ed.), ISBN: 978-953-51-0603-6, InTech, Available from: http://www.intechopen.com/books/muscular-dystrophy/muscle-satellite-cells-and-musculardystrophy

\section{INTECH}

open science | open minds

\section{InTech Europe}

University Campus STeP Ri

Slavka Krautzeka 83/A

51000 Rijeka, Croatia

Phone: +385 (51) 770447

Fax: +385 (51) 686166

www.intechopen.com

\section{InTech China}

Unit 405, Office Block, Hotel Equatorial Shanghai

No.65, Yan An Road (West), Shanghai, 200040, China

中国上海市延安西路 65 号上海国际贵都大饭店办公楼 405 单元

Phone: +86-21-62489820

Fax: $+86-21-62489821$ 
(C) 2012 The Author(s). Licensee IntechOpen. This is an open access article distributed under the terms of the Creative Commons Attribution 3.0 License, which permits unrestricted use, distribution, and reproduction in any medium, provided the original work is properly cited. 